\title{
A Rare Cause of Gastrointestinal Bleeding: Cholecystoenteric Fistula
}

\author{
Iliass Charif ${ }^{*}$, Hossam Benhammane², Dafr-Allah Benajah', Said Ait Laalim², \\ Khalid Mazaz ${ }^{2}$, Adil Ibrahimi ${ }^{1}$, Mounia El Yousfi ${ }^{1}$ \\ ${ }^{1}$ Department of Gastroenterology, Hassan II University Hospital, Faculty of Medicine and Pharmacy of Fez, \\ Sidi Mohammed Ben Abdellah University, Fez, Morocco \\ ${ }^{2}$ Department of Surgery, Hassan II University Hospital, Faculty of Medicine and Pharmacy of Fez, \\ Sidi Mohammed Ben Abdellah University, Fez, Morocco \\ Email: ${ }^{*}$ iliass82@yahoo.fr
}

Received 10 July 2014; revised 8 August 2014; accepted 3 September 2014

Copyright (C) 2014 by authors and Scientific Research Publishing Inc.

This work is licensed under the Creative Commons Attribution International License (CC BY).

http://creativecommons.org/licenses/by/4.0/

c) (i) Open Access

\begin{abstract}
A 60-year-old woman presented to the emergency department of our university hospital for several episodes of upper gastro-intestinal bleeding (hematemesis and melena). The endoscopic examination (Figure 1) showed a large ulcer at the front of the bulb, with a calculation within it and a visible vessel on the banks of the ulcer treated by putting two clips. Computer tomography (CT), demonstrated a sclerotic, atrophic and multi gallstone gallbladder, with a calculation protruding in the duodenum. The patient underwent surgery which consisted on partial cholecystectomy with duodenal suture and closing of cystic duct.
\end{abstract}

\section{Keywords}

Gastrointestinal Bleeding, Cholecystoenteric Fistula

\section{Introduction}

Acute upper gastrointestinal bleeding is a common medical emergency that could involve the vital prognosis. The etiologies are many: some are common, others are rare. Among the very rare etiologies, the fistulas whose diagnosis can be done by endoscopy and imaging and treatment is usually surgical.

\section{Case Report}

A 60-year-old woman presented to the emergency department of our university hospital for several episodes of

\footnotetext{
${ }^{*}$ Corresponding author.
}

How to cite this paper: Charif, I., Benhammane, H., Benajah, D.-A., Laalim, S.A., Mazaz, K., Ibrahimi, A. and El Yousfi, M. (2014) A Rare Cause of Gastrointestinal Bleeding: Cholecystoenteric Fistula. Case Reports in Clinical Medicine, 3, $521-523$. 
upper gastro-intestinal bleeding (hematemesis and melena), the first of which dated to 3 days. On examination, hemodynamic parameters were correct. At admission, her haemoglobin was $6.9 \mathrm{~g} / \mathrm{dl}$, platelet count $213.000 / \mathrm{mcl}$, prothrombin time $87 \%$ and liver test didn't show any abnormality. The endoscopic examination (Figure 1) showed a large ulcer at the front of the bulb, with a calculation within it and a visible vessel on the banks of the ulcer treated by putting two clips to prevent bleeding reccurence.

Computer tomography (CT), demonstrated a sclerotic, atrophic and multi gallstone gallbladder, with a calculation protruding in the duodenum (Figure 2). Several mechanisms have been reported in the literature explaining

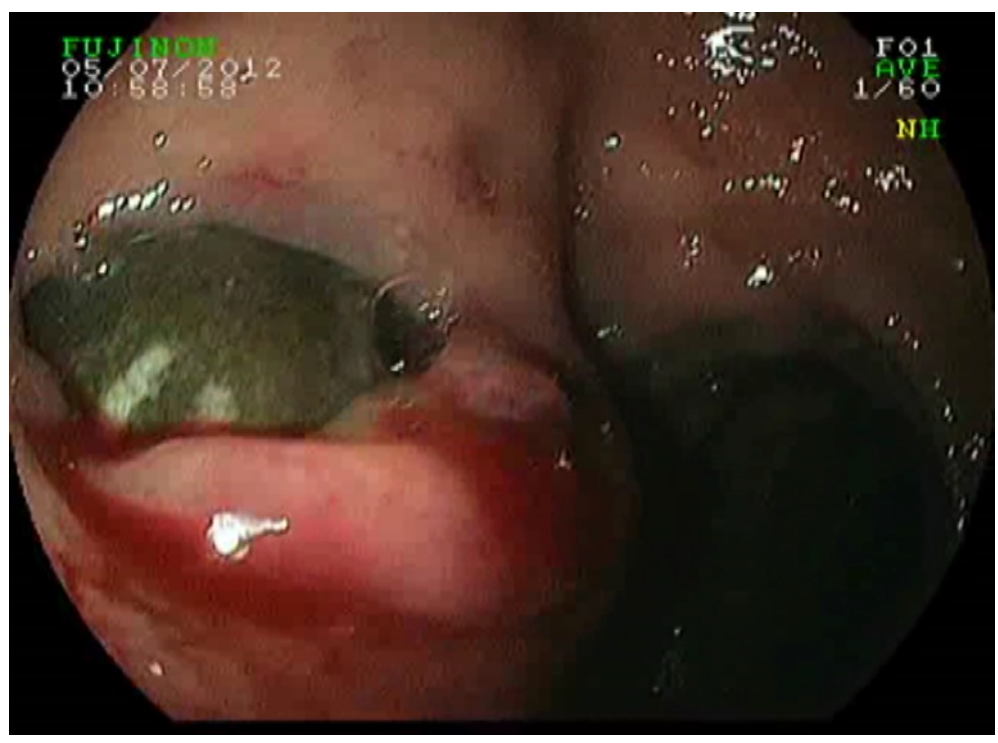

Figure 1. Large ulcer at the front of the bulb with a calculation within it.

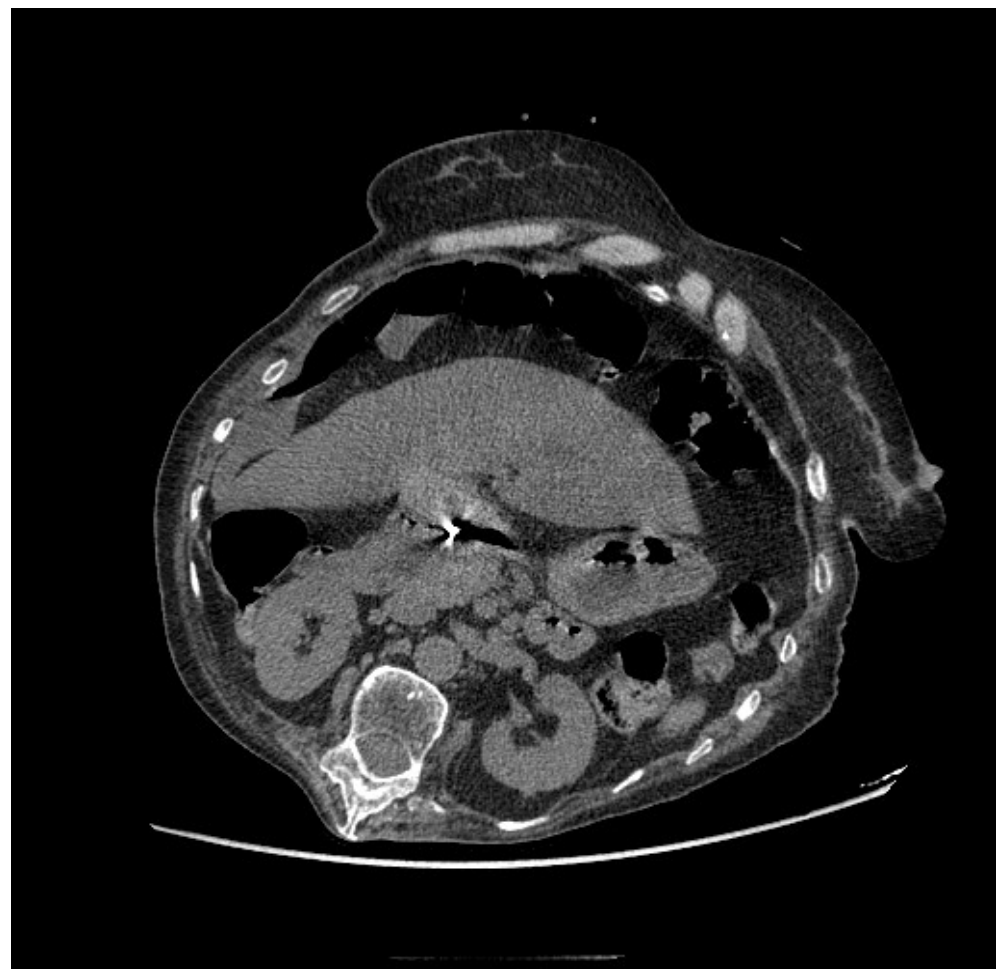

Figure 2. Sclerotic, atrophic gallbladder, with a calculation protruding in the duodenum. 
the appearance of this kind of fistula, including pseudoaneurysm and haemobilia [1]-[3]. The patient underwent surgery which consisted on partial cholecystectomy with duodenal suture and closing of cystic duct.

\section{Conclusion}

Via this case, we want to attract attention to this rare cause of gastrointestinal bleeding, and we emphasize the importance of careful endoscopic examination in upper gastrointestinal bleeding to be able to reveal this kind of causes. CT performed by an expert can help in diagnosis. Surgery is the standard treatment for this cause of upper gastrointestinal bleeding.

\section{Study Highlights}

- Bilio-digestive fistula as rare disease.

- Bilio-digestive fistula as a rare cause of gastrointestinal bleeding.

- The importance of careful endoscopy.

- The importance of imaging (CT).

- Surgery as the standard treatment.

\section{References}

[1] Saluja, S.S., Ray, S., Gulati, M.S., Pal, S., Sahni, P. and Chattopadhyay, T.K. (2007) Acute Cholecystitis with Massive Upper Gastrointestinal Bleed: A Case Report and Review of the Literature. BMC Gastroenterology, 7, 12. http://dx.doi.org/10.1186/1471-230X-7-12

[2] Nana, G.R., Gibson, M., Speirs, A. and Ramus, J.R. (2013) Upper Gastrointestinal Bleeding: A Rare Complication of Acute Cholecystitis. International Journal of Surgery Case Reports, 4, 761-764. http://dx.doi.org/10.1016/j.ijscr.2013.05.016

[3] Glaysher, M.A., Cruttenden-Wood, D. and Szentpali, K. (2014) A Rare Cause of Upper Gastrointestinal Haemorrhage: Ruptured Cystic Artery Pseudoaneurysm with Concurrent Cholecystojejunal Fistula. International Journal of Surgery Case Reports, 5, 1-4. http://dx.doi.org/10.1016/j.ijscr.2013.11.005 
Scientific Research Publishing (SCIRP) is one of the largest Open Access journal publishers. It is currently publishing more than 200 open access, online, peer-reviewed journals covering a wide range of academic disciplines. SCIRP serves the worldwide academic communities and contributes to the progress and application of science with its publication.

Other selected journals from SCIRP are listed as below. Submit your manuscript to us via either submit@scirp.org or Online Submission Portal.
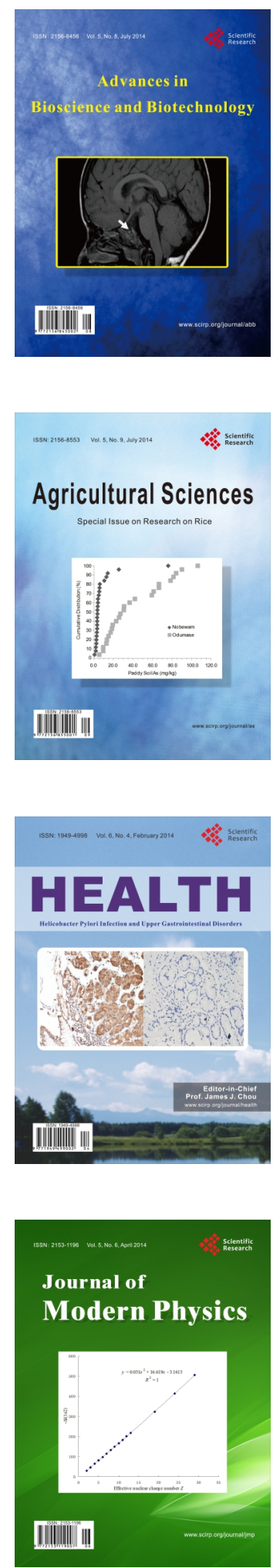
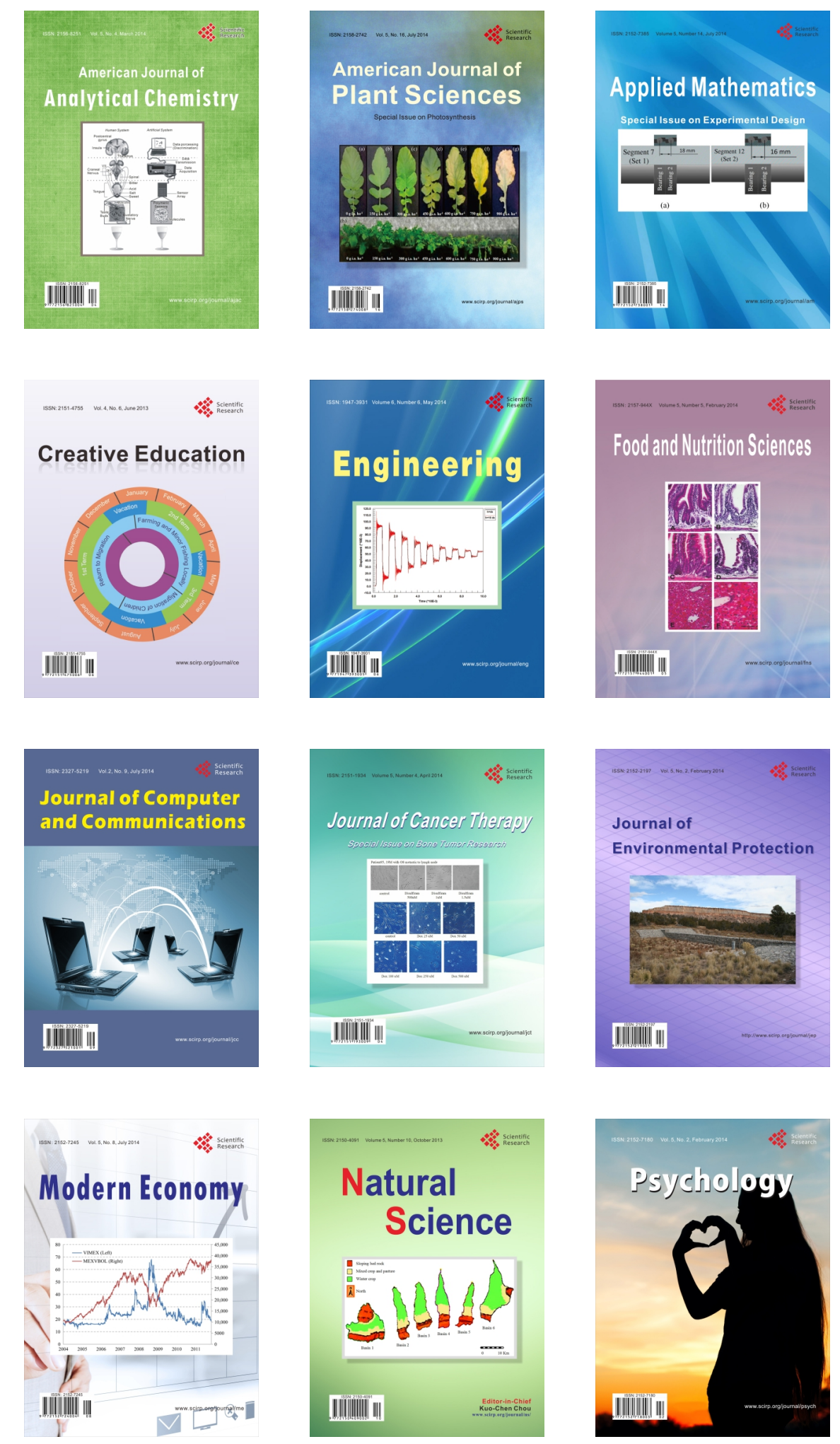